\title{
Ketamine Cystitis: An Underrecognized Cause of Dysuria
}

\author{
Eric Kutscher, $M D^{1,2}$ (]) and Richard E. Greene, MD, MHPE ${ }^{1,2}$ \\ ${ }^{1}$ Internal Medicine, NYU Langone Health, New York, NY, USA; ${ }^{2}$ Internal Medicine, Bellevue Hospital Center, New York, NY, USA.
}

KEY WORDS: substance use; ketamine; sexual health.

J Gen Intern Med 37(5):1286-9

DOI: $10.1007 /$ s1 1606-021-07297-0

(c) The Author(s) under exclusive licence to Society of General Internal Medicine 2021

\section{INTRODUCTION}

Urinary concerns are common in primary care. ${ }^{1}$ Among men with urinary symptoms, sexually transmitted infections are often additionally considered. Ketamine-induced cystitis, though common within the urology literature, is not often seen or diagnosed in the primary care setting.

\section{CLINICAL PRESENTATION}

A 28-year-old man without significant medical history presented to primary care with worsening urinary urgency, frequency, and dysuria for 6 months. The patient's symptoms started insidiously and progressively worsened, where upon presentation he felt the urge to urinate every 20 to $60 \mathrm{~min}$, urinating small quantities and occasionally having urge incontinence, causing him to wear a diaper whenever leaving the house. The patient also reported significant penile pain, with a constant burning sensation that worsened with urination. His urine was described as clear but with a few episodes of terminal gross hematuria. He denied any penile discharge or lesions, as well as any testicular pain. He reported being sexually active with multiple male partners, always as the insertive partner, using pre-exposure prophylaxis (PrEP) "on demand" and intermittent condom usage for HIV prevention. He denied a history of sexually transmitted infections. He reported smoking cigarettes since age 16 with a 9 pack-year history, and with prior heavy alcohol use in his early 20 s ( 8 drinks nightly for 4 years, then decreased to 3 drinks three times weekly since). He previously had tried marijuana, 3,4methylenedioxymethamphetamine, (MDMA), 3,4methylenedioxyamphetamine (MDA), gamma hydroxybutyrate (GHB), and lysergic acid diethylamide (LSD). The patient also reported consistent use of recreational intranasal ketamine for the past 9 years with progressively increasing frequency, with use at presentation of $4000 \mathrm{mg}$ of

Received June 17, 2021

Accepted November 23, 2021

Published online January 3, 2022 ketamine per day. Though he had initially used ketamine only in the setting of raves and electronic music festivals, his use increased during the lockdown phase of the COVID-19 pandemic due to increased access, and he denied any underlying mood or anxiety symptoms for which he was attempting to self-medicate.

The patient was initially evaluated for his symptoms at an outside clinic, where he was treated empirically for gonorrhea (GC) with one dose azithromycin $2 \mathrm{~g}$. His initial encounter at our clinic 2 weeks later was performed via telephone visit due to COVID-19 pandemic-related restrictions, so a genitourinary exam was unable to be performed. Labs were obtained, notable for a basic metabolic profile with normal creatinine and a urinalysis with clear yellow urine with moderate blood and trace protein, negative leukocyte esterase, and negative nitrites, 3-6 WBCs/HPF and 11-20 RBC/HPF. Urine culture showed no growth. Urine gonorrhea and chlamydia tests were negative, and oropharyngeal GC amplification was positive. Given the persistence of his symptoms and the degree of his discomfort, the patient was treated for oropharyngeal GC with ceftriaxone $500 \mathrm{mg}$ IM followed by 2 weeks of doxycycline to cover for possible nongonococcal urethritis, as well as diclofenac to treat for possible inflammatory aseptic prostatitis. His symptoms did not improve over the subsequent 2 weeks and he was referred to urological colleagues for evaluation. Repeat evaluation with physical exam revealed a normal urethral, penile, and testicular exam, and a normal digital rectal exam without nodules, induration, or tenderness. Bedside ultrasound showed a normal post-void residual. Repeat UA showed large blood, small leukocyte esterase, 4-6 squamous cells, 21-50 WBCs/HPF, >50 RBCs/HPF, 4-6 hyaline casts/ $\mathrm{HPF}$, and had a $\mathrm{pH}>9.0$. CT urogram showed asymmetrical thickening of the urinary bladder. The patient underwent a cystoscopy showing diffuse erythema primarily along the posterior wall near the dome of the bladder without mucosal lesions or tumors. Pathology samples revealed acute inflammation without dysplasia, consistent with interstitial cystitis. Though cigarette smoking and alcohol, known bladder irritants, were considered as potential contributors, he was ultimately diagnosed with ketamine-induced cystitis given his exceedingly high doses of ketamine.

The patient was started on oxybutynin extended-release with slight improvement in his symptoms but still voiding every $30 \mathrm{~min}$. He was trialed on gabapentin $300 \mathrm{mg}$ three times daily without relief, and then offered pentosan polysulfate which he declined due to concerns over side 
effects. He was counseled on abstinence from ketamine as treatment for his cystitis, but struggled with cessation. Given his excessive dosing of ketamine, persistent use with unsuccessful efforts to cut down, and continued use despite having physical problems caused by ketamine, the patient was diagnosed with phencyclidine use disorder under DSM-V criteria where ketamine is classified due to its pharmacologic similarities with phencyclidines. He was referred to a cognitive behavioral therapist, but on his own started abstaining from ketamine with mild improvement of symptoms in 2 weeks. The patient heard anecdotal evidence from other people using ketamine that epigallocatechin gallate (EGCG) would improve his symptoms, and began self-administering the supplement 2 weeks after initiation of abstinence, along with additional supplements from a commercial vendor 3 weeks after initiation of abstinence. At week 4, the patient noticed significant improvement in his urinary symptoms with decreased urinary frequency (urinating every 3-4 h) and resolved hematuria, but persistent dysuria. Four months after abstinence, the patient began using recreational ketamine at much lower doses ( $1 \mathrm{~g}$ per week in social settings), with worsening of symptoms on days of ketamine use. He declined abstinence strategies and opted to try harm reduction techniques learned from other ketamine users including consumption of significant volumes of water (8 1 per day), and drinking EGCG-containing green tea and white grapefruit cocktails when using ketamine to decrease his cystitis symptoms. He continued to report an exacerbation of symptoms when using ketamine, though experienced these more mildly when simultaneously attempting harm reduction techniques.

\section{DISCUSSION}

We report a case of a patient with ketamine cystitis presenting to primary care for initial management. This condition caused significant distress for this young patient and posed a diagnostic dilemma that did not respond to initial empirical treatments. It is important for primary care providers to consider and evaluate for ketamine cystitis, and to feel equipped to have informed discussions with patients using ketamine about its possible impacts on their health.

Ketamine is approved by the FDA only for induction and maintenance of anesthesia. However, ketamine use is expanding, particularly among young adults, ${ }^{2}$ and is most commonly seen among young men in urban settings. ${ }^{3}$ The National Institute on Drug Abuse estimates 3 million people have used ketamine as a recreational agent at least once in their lives, including $1.3 \%$ of all 12 th graders in $2020 .^{2}$ Ketamine's utility in management of depression is under review, ${ }^{4}$ yet many press outlets have covered this area of research in a positive light. Given these trends, ketamine cystitis may become more common in the primary care setting.

Ketamine is a derivative of phencyclidine (PCP). Ketamine is as an N-methyl-D-aspartate (NMDA)-receptor non- competitive antagonist that can be used intravenously (IV), intramuscular (IM) injections, orally, intranasally, rectally, subcutaneously, and epidurally. ${ }^{4}$ Ketamine is dosedependent, with lower doses often acting as a stimulant with mild hallucinations, and higher doses causing greater dissociations from reality. Acute psychiatric effects result in CNS depression and a feeling of intoxication, altered auditory, visual, and somatosensory perceptions, referential ideas and delusions, and negative symptoms (such as poverty of speech). ${ }^{5}$ Aside from its main NMDA antagonism, ketamine affects several other pathways with various physiologic consequences. For example, ketamine works as an antagonist on calcium channel blockers causing negative inotropy ${ }^{6}$ and smooth muscle relaxation of the airway. ${ }^{7}$ Its inhibition of voltage gated sodium channels results in decreased parasympathetic activity ${ }^{8}$ and local anesthetic effects. ${ }^{9}$ Ketamine's interactions with BK channels have also been shown to provide analgesia for neuropathic pain. ${ }^{10}$ Agonism on opioid receptors are postulated to improve pain response, ${ }^{11}$ and $\alpha$ amino-3-hydroxy-5-methyl-4-isoxazolepropionic acid (AMPA) receptor upregulation is postulated to explain ketamine's witnessed rapid anti-depressant effects. ${ }^{12}$

Recreationally, ketamine is often called special $\mathrm{K}$, vitamin $\mathrm{K}$, Kit Kat, jet, cat valium, and liquid E. ${ }^{13}$ Recreational ketamine use often entails higher doses of ketamine (100-200 mg per dose) with multiple doses per day to prolong intoxication. ${ }^{13}$ Overdose events from ketamine alone are generally not lethal, although complications due to psychosis and dissociation can be significant. ${ }^{13}$ Larger risks exist in coadministration of drugs ${ }^{3}$ and lack of awareness to surrounding environment resulting in accidents. ${ }^{14}$ Long-term misuse of recreational ketamine has been shown to cause profound cognitive impairments in short- and long-term memory. ${ }^{15}$

First reported in a case series by Shahani et al. in 2007, ${ }^{16}$ ketamine cystitis has become a phenomenon seen in over a quarter of regular recreational ketamine users. ${ }^{17}$ The typical presentation of ketamine cystitis is severe dysuria, urgency, frequency, and gross hematuria. ${ }^{16}$ Though most cases occur in active recreational ketamine users, one case study found ketamine cystitis in a patient abstinent from ketamine use for 7 years. ${ }^{18(p)}$ Workup often shows negative urine urinalysis, culture, CT scan with thickened bladder walls, and cystoscopy showing severe ulcerative cystitis. ${ }^{16}$ Biopsies, when obtained, reveal epithelial denudation, inflammation, and a mild eosinophilic infiltrate. ${ }^{16}$ The pathophysiology of ketamine cystitis remains unclear, but the metabolites of ketamine are highly concentrated in urine,${ }^{19}$ and therefore assumed to cause irritation of the bladder, resulting in eosinophilic infiltration. ${ }^{20}$ The duration and frequency of misuse has been correlated with severity of symptoms and degree of urinary tract damage. ${ }^{21}$

The mainstay treatment for ketamine cystitis is abstinence, with $51 \%$ of patients reporting improvement in symptoms after stopping use. ${ }^{17}$ Treatment with steroids or antibiotics is often unsuccessful at controlling symptoms. Pentosan polysulfate is frequently used for cases of interstitial cystitis 
with a proposed mechanism of restoration of epithelial barrier integrity in the bladder. ${ }^{22}$ For patients with ketamine cystitis, use of pentosan polysulfate may have some degree of symptomatic relief, ${ }^{16}$ though there is an association between pentosan polysulfate and progressive maculopathy that raises concern about regular use of this medication. ${ }^{23}$

A complicated overlap exists between recreational ketamine use, mental health, and addiction. Many patients using recreational ketamine have underlying depression and anxiety which they try to manage with ketamine self-medication. ${ }^{24}$ Recreational ketamine use can develop into a ketamine use disorder, listed within the DSM-V within phencyclidine use disorder, with the main differentiation involving significant impairment or distress from continued use. Mainstay treatment for PCP substance use disorders involves cognitive and behavioral therapy. Medical management with lamotrigine has been found to successfully decrease drug cravings in one case study among people using ketamine. ${ }^{25}$

Aside from addiction treatment, harm reduction methodologies around ketamine require further research, particularly with regard to risk of ketamine cystitis. Some people using ketamine have reported harm reduction methods to decrease risks of excessive dissociation (entering the "K-Hole") through spacing out sessions of use, spacing out doses during a session, and limiting the amount of ketamine used at one time. ${ }^{26}$ Our patient additionally tried using EGCG to alleviate his symptoms, as well as white grapefruit juice to increase his euphoric response to ketamine at lower doses. Interestingly, a study of EGCG administration with ketamine in rats showed reduced ketamine-induced fibrosis and inflammatory changes, ${ }^{27}$ and a separate study showed use of grapefruit juice $200 \mathrm{ml}$ three times per day for 5 days increased ketamine's peak plasma concentration and half-life elimination among 12 healthy volunteers in a crossover study. ${ }^{28}$ Given the likely dose-dependent relationship between ketamine use and ketamine cystitis, further research is needed to understand if these harm reduction methods decrease the risk of developing ketamine cystitis, or improve symptoms for patients already living with ketamine cystitis.

Corresponding Author: Eric Kutscher, MD; Internal Medicine, Bellevue Hospital Center, New York, NY, USA (e-mail: Eric. Kutscher@nyulangone.org).

\section{REFERENCES}

1. Finley CR, Chan DS, Garrison S, et al. What are the most common conditions in primary care? Can Fam Physician 2018;64(11):832-840.

2. Abuse NI on D. Monitoring the Future Study: Trends in Prevalence of Various Drugs. National Institute on Drug Abuse. Published December 17, 2020. https://www.drugabuse.gov/drug-topics/trends-statistics/ monitoring-future/monitoring-future-study-trends-in-prevalence-various-drugs Accessed 18 March 2021

3. Ni A, Lee Cantrell F, Clark RF. Ketamine exposure demographics and outcomes over 16 years as reported to US poison centers. Am $J$ Emerg Med 2018;36(8):1459-1462. https://doi.org/10.1016/j.ajem.2018.04. 066
4. Li L, Vlisides PE. Ketamine: 50 Years of Modulating the Mind. Front Hum Neurosci 2016; 10:612. https://doi.org/10.3389/fnhum.2016.00612

5. Pomarol-Clotet E, Honey GD, Murray GK, et al. Psychological effects of ketamine in healthy volunteers: Phenomenological study. Br J Psychiatry 2006;189(2):173-179. https://doi.org/10.1192/bjp.bp. 105.015263

6. Baum VC, Tecson ME. Ketamine inhibits transsarcolemmal calcium entry in guinea pig myocardium: Direct evidence by single cell voltage clamp. Anesth Analg. 1991;73(6):804-807. https://doi.org/10.1213/ 00000539-199112000-00022

7. Yamakage M, Hirshman CA, Croxton TL. Inhibitory effects of thiopental, ketamine, and propofol on voltage-dependent calcium sup 2+ channels in porcine tracheal smooth muscle cells. Anesthesiology. 1995;83(6):12741282. https://doi.org/10.1097/00000542-199512000-00018

8. Irnaten M, Wang J, Chang KSK, Andresen MC, Mendelowitz D. Ketamine inhibits sodium currents in identified cardiac parasympathetic neurons in nucleus ambiguus. Anesthesiology. 2002;96(3):659-666. https://doi. org/10.1097/00000542-200203000-00023

9. Frenkel C, Urban BW. Molecular actions of racemic ketamine on human cns sodium channels $\dagger$. Br J Anaesth 1992;69(3):292-297. https://doi. org/10.1093/bja/69.3.292

10. Hayashi Y, Kawaji K, Sun L, et al. Microglial CA2+-activated K+ channels are possible molecular targets for the analgesic effects of s-ketamine on neuropathic pain. J Neurosci 2011;31(48):17370-17382. https://doi.org/ 10.1523/JNEUROSCI.4152-11.2011

11. Finck AD, Ngai SH. Opiate Receptor Mediation of Ketamine Analgesia. Anesthesiology. 1982;56(4):291-297. https://doi.org/10.1097/ 00000542-198204000-00011

12. Zanos P, Moaddel R, Morris PJ, et al. NMDAR inhibition-independent antidepressant actions of ketamine metabolites. Nature. 2016;533(7604):481-486. https://doi.org/10.1038/nature17998

13. Sassano-Higgins S, Baron D, Juarez G, Esmaili N, Gold M. A review of ketamine abuse and diversion. Depress Anxiety 2016;33(8):718-727. https://doi.org/10.1002/da.22536

14. Morgan CJA, Curran HV. Ketamine use: A review. Addiction. 2012;107(1):27-38. https://doi.org/10.1111/j.1360-0443.2011.03576.x

15. Morgan CJA, Muetzelfeldt L, Curran HV. Consequences of chronic ketamine self-administration upon neurocognitive function and psychological wellbeing: A 1-year longitudinal study. Addiction 2010;105(1):121-133. https://doi.org/10.1111/j.1360-0443.2009. 02761.x

16. Shahani R, Streutker C, Dickson B, Stewart RJ. Ketamine-associated ulcerative cystitis: A new clinical entity. Urology. 2007;69(5):810-812. https://doi.org/10.1016/j.urology.2007.01.038

17. Winstock AR, Mitcheson L, Gillatt DA, Cottrell AM. The prevalence and natural history of urinary symptoms among recreational ketamine users. BJU Int 2012;110(11): 1762-1766. https://doi.org/10.1111/j.1464-410X. 2012.11028.x

18. Robles-Martinez M, Abad AC, Pérez-Rodríguez V, Ros-Cucurull E, Esojo A, Roncero C. Delayed urinary symptoms induced by ketamine. $J$ Psychoactive Drugs 2018;50(2):129-132. https://doi.org/10.1080/ 02791072.2017.1371364

19. Moore KA, Sklerov J, Levine B, Jacobs AJ. Urine concentrations of ketamine and norketamine following illegal consumption. J Anal Toxicol 2001;25(7):583-588. https://doi.org/10.1093/jat/25.7.583

20. Jhang J-F, Hsu Y-H, Kuo H-C. Possible pathophysiology of ketaminerelated cystitis and associated treatment strategies. Int $J$ Urol Off $J$ Jpn Urol Assoc 2015;22(9):816-825. https://doi.org/10.1111/iju.12841

21. Chu PS-K, Ma W-K, Wong SC-W, et al. The destruction of the lower urinary tract by ketamine abuse: A new syndrome? BJU Int 2008;102(11):1616-1622. https://doi.org/10.1111/j.1464-410X.2008. 07920.x

22. Teichman JM. The Role of Pentosan Polysulfate in Treatment Approaches for Interstitial Cystitis. Rev Urol 2002;4(Suppl 1):S21-S27.

23. Jain N, Li AL, Yu Y, VanderBeek BL. Association of macular disease with long-term use of pentosan polysulfate sodium: Findings from a US cohort. $\mathrm{Br} J$ Ophthalmol 2020;104(8):1093-1097. https://doi.org/10. 1136/bjophthalmol-2019-314765

24. Chen L-Y, Chen C-K, Chen C-H, Chang H-M, Huang M-C, Xu K. Association of craving and depressive symptoms in ketamine-dependent patients undergoing withdrawal treatment. Am J Addict 2020;29(1):4350. https://doi.org/10.1111/ajad.12978

25. Huang M-C, Chen L-Y, Chen C-K, Lin S-K. Potential benefit of lamotrigine in managing ketamine use disorder. Med Hypotheses 2016;87:97-100. https://doi.org/10.1016/j.mehy.2015.11.011

26. Vidal Giné C, Fernández Calderón F, López Guerrero J. Patterns of use, harm reduction strategies, and their relation to risk behavior and harm in 
recreational ketamine users. Am J Drug Alcohol Abuse 2016;42(3):358369. https://doi.org/10.3109/00952990.2016.1141211

27. Jang M-Y, Lee Y-L, Long C-Y, et al. The protective effect of green tea catechins on ketamine-induced cystitis in a rat model. Urol Sci 2015;26(3):186-192. https://doi.org/10.1016/j.urols.2015.07.010

28. Peltoniemi MA, Saari TI, Hagelberg NM, Laine K, Neuvonen PJ, Olkkola KT. S-ketamine concentrations are greatly increased by grapefruit juice.
Eur J Clin Pharmacol 2012;68(6):979-986. https://doi.org/10.1007/ s00228-012-1214-9

Publisher's Note: Springer Nature remains neutral with regard to jurisdictional claims in published maps and institutional affiliations. 